Check for updates

Cite this: RSC Adv., 2019, 9, 10754

\title{
Quantum-dot light-emitting diode with ultrathin Au electrode embedded in solution-processed phosphomolybdic acid $\dagger$
}

\author{
Maciej Chrzanowski, (D) * Mateusz Banski, DD Piotr Sitarek, Jan Misiewicz \\ and Artur Podhorodecki*
}

We proposed to exploit phosphomolybdic acid (PMA) as a cost-efficient $\mathrm{MoO}_{x}$ source for combined spincoating/sputtering/spin-coating deposition of a $\mathrm{MoO}_{x} / \mathrm{Au} / \mathrm{MoO}_{x}(\mathrm{MAM})$ composite electrode. The bottom PMA layer provides perfect wetting conditions for ultrathin Au film sputtering and prevents the formation of gold islands on the glass surface, while the top PMA layer helps to reduce light reflection. By optimizing the thickness of ultrathin Au films and PMA layers, we achieved maximum transmittance of $79 \%$ at $550 \mathrm{~nm}$ and a sheet resistance of only $22 \Omega \mathrm{sq}^{-1}$ which is comparable to the resistance of ITO substrates (20 $\Omega \mathrm{sq}^{-1}$ ). MAM multilayer was explored both as a transparent electrode and as a hole injection layer (HIL) to eliminate ITO and PEDOT:PSS from solution-processed quantum-dot light-emitting diodes (QLEDs). The fabricated MAM-based QLED shows a peak external quantum efficiency (EQE) of $2.7 \%$ and maximum brightness of $12000 \mathrm{~cd} \mathrm{~m}^{-2}$ at $7 \mathrm{~V}$. By performing bending tests of the polyethylene (PET) substrate coated with MAM electrode, we demonstrate that it is also a promising candidate for flexible transparent optoelectronics.

Received 5th March 2019

Accepted 1st April 2019

DOI: $10.1039 / \mathrm{c} 9 \mathrm{ra01680e}$

rsc.li/rsc-advances in dielectric layers of vacuum-deposited high refractive index oxides which are responsible for reflectance reduction due to light coupling with surface plasmon polaritons (SPP) at a metal/ oxide interface. ${ }^{21}$ These oxide/metal/oxide multilayers have been already investigated in various combinations including metal oxides: $\mathrm{MoO}_{3}{ }^{22,23} \mathrm{WO}_{3}{ }^{24,25} \mathrm{ZnO},{ }^{26} \mathrm{ZnS},{ }^{27}$ as well as different metals: gold, ${ }^{28}$ silver, ${ }^{29}$ or copper. ${ }^{30}$ Although silver is the most promising metal due to its champion conductivity and low cost, it has a lower work function in contrast to gold which is tailored better to most of organic hole transport layers (HTLs).

In this paper, we propose to use cost-efficient solutionprocessed phosphomolybdic acid (PMA) instead of thermally evaporated $\mathrm{MoO}_{3}$ to fabricate MAM multilayer. We describe the procedure of deposition and transmittance optimization of ultrathin $\mathrm{Au}$ film embedded in PMA bilayer and demonstrate that it can be applied to regular bottom-emitting QLED where it serves as a bi-functional layer, i.e. transparent electrode and hole injection layer (HIL). In the end, the MAM electrode is examined in the context of flexible QLED fabrication.

\section{Results and discussion}

\section{MAM multilayer optimization}

Surface morphology of ultrathin metal films is particularly important for their electrical and optical properties, as it was already shown that discontinuous formations such as islands, grains, or perforations might have a detrimental effect on transparency and resistance. ${ }^{31-34}$ Deposition of nucleation layer 
has been recognized as an effective approach to improve the homogeneity of the metal film. Metal oxides or ultrathin metal layer is typically introduced to assure continuous layer growth, although other techniques, e.g. metal doping, have been also proposed..$^{23}$ Molybdenum oxide $\left(\mathrm{MoO}_{3}\right)$ is particularly favoured as a wetting layer because it can serve simultaneously as a hole injection layer (HIL) and is compatible with optoelectronic applications.

We proposed to use combined sequential spin-coating/ sputtering/spin-coating method to deposit $\mathrm{MoO}_{x} / \mathrm{Au} / \mathrm{MoO}_{x}$ multilayer electrode which is time-saving and cost-efficient compared to thermal evaporation. There are several solutionprocessed $\mathrm{MoO}_{x}$ precursors including phosphomolybdic acid hydrate (PMAH) ${ }^{35}$ ammonium molybdate, ${ }^{36}$ molybdenyl acetylacetonate $\left(\mathrm{MoO}_{2}(\mathrm{Acac})_{2}\right){ }^{37} \mathrm{MoO}_{3}$ nanoparticles, ${ }^{38}$ or peroxomolybdic acid. ${ }^{39}$ Among them, PMAH, which is heteropoly acid containing $\mathrm{MoO}_{3}$ units closed within Keggin structure, has been identified as particularly versatile $\mathrm{MoO}_{x}$ precursor because of its high solubility in polar solvents, tunable work function, low thin film surface roughness, and relatively low post-annealing temperature..$^{35,40}$ Importantly, PMA has been already examined as the HIL in organic photovoltaic cells (OPVs) ${ }^{41}$ OLEDs ${ }^{35}$ and recently, also in QLEDs. ${ }^{42,43}$

During deposition of PMA/Au/PMA multilayer, we encountered a problem of dissolving the bottom PMA layer by the top PMA. To solve that problem, we used a procedure of PMA reduction by baking PMA before thin film deposition. The baking process under oxygen-free conditions causes partial reduction of $\mathrm{Mo}(\mathrm{vI})$ to $\mathrm{Mo}(\mathrm{v})$ which results in a gradual colour change from green to bluish (see Fig. S1a-c, ESI $\dagger$ ). Reduced PMA has been already proposed as a post-annealing free HIL in OLED device, ${ }^{44}$ and it seems to be suitable for roomtemperature processing of flexible conductive substrates. Reduced PMA is more soluble in acetonitrile (ACN) that in isopropanol (IPA), but we noticed that thin films prepared by spin-coating are easily flushed by ACN while IPA has no effect on film thickness. Additionally, the stability of reduced PMA is much better when stored in IPA. ${ }^{44}$

Except for $\mathrm{Au}, \mathrm{Ag}$ thin film was also examined as a conductive interlayer but we discovered that PMA etches Ag due to its acidic nature forming a bluish solution which might indicate the reduction of $\mathrm{Mo}(\mathrm{vr})$ oxidation state to $\mathrm{Mo}(\mathrm{v})$. Although reduced PMA is no longer aggressive to Ag, its incorporation into PMA/ $\mathrm{Ag} / \mathrm{PMA}$ electrode requires further investigation and is beyond the scope of this paper.

$\mathrm{Au}$ films were deposited on cleaned quartz coated glass by sputtering with a constant rate and the thickness of films was determined by atomic force microscopy (AFM) (Fig. S2, $\operatorname{ESI}_{\dagger} \dagger$ ). However, obtained Au films have poor transmittance especially in the longer wavelength region (Fig. 1a). The characteristic shape of transmission is readily attributed to the presence of $\mathrm{Au}$ grains instead of the continuous layer. The absorption in the blue wavelength region increases with thicker films and is affected by the absorption of light by interband electronic transitions. ${ }^{45}$ The maxima located at 500-520 $\mathrm{nm}$ are associated with light absorption on free electrons, whereas transmission minima in the red region of spectra might be explained by excitation of localized surface plasmon-polariton (SPP) which depends on size and shape of Au grains. ${ }^{46}$ The redshift of minima for thicker Au films is connected to a larger size of these grains. AFM image of Au film on glass reveals a corrugated surface with lots of perforations (Fig. S3a, ESI $\dagger$ ). Such poor morphology might arise both from low wettability of glass and its rough surface (RMS $=1.0 \mathrm{~nm}$ ). The sheet resistances of $\mathrm{Au}$ films deposited for $20 \mathrm{~s}$ and $19 \mathrm{~s}$ are 266 and $133 \Omega \mathrm{sq}^{-1}$, respectively, but they exceed $10^{6} \Omega \mathrm{sq}^{-1}$ for all thinner samples indicating discontinuous nature of these films and lack of percolation pathways.

In contrast to bare $\mathrm{Au}$ films, PMA/Au films have superior transmittance with a peak located between 550 and $600 \mathrm{~nm}$ (Fig. 1a). Minima in the red region, which are distinctive for SPP in grainy films, are no longer observed that suggests continuous films formation. The thicker $\mathrm{Au}$ film, the higher transmittance enhancement in the red region of the spectrum is observed. At the same time, absorption in the blue region increases. Sheet resistances of all PMA/Au bilayers are below $60 \Omega \mathrm{sq}^{-1}$ (Fig. 1b). Analysis of AFM images confirms that PMA, which surface has RMS roughness of only $0.22 \mathrm{~nm}$, provides perfect conditions for continuous and smooth Au film growth (Fig. S3a, ESI†). RMS roughness of PMA/Au (shown in Fig. S3c, ESI $\dagger$ ) is $0.33 \mathrm{~nm}$ and is
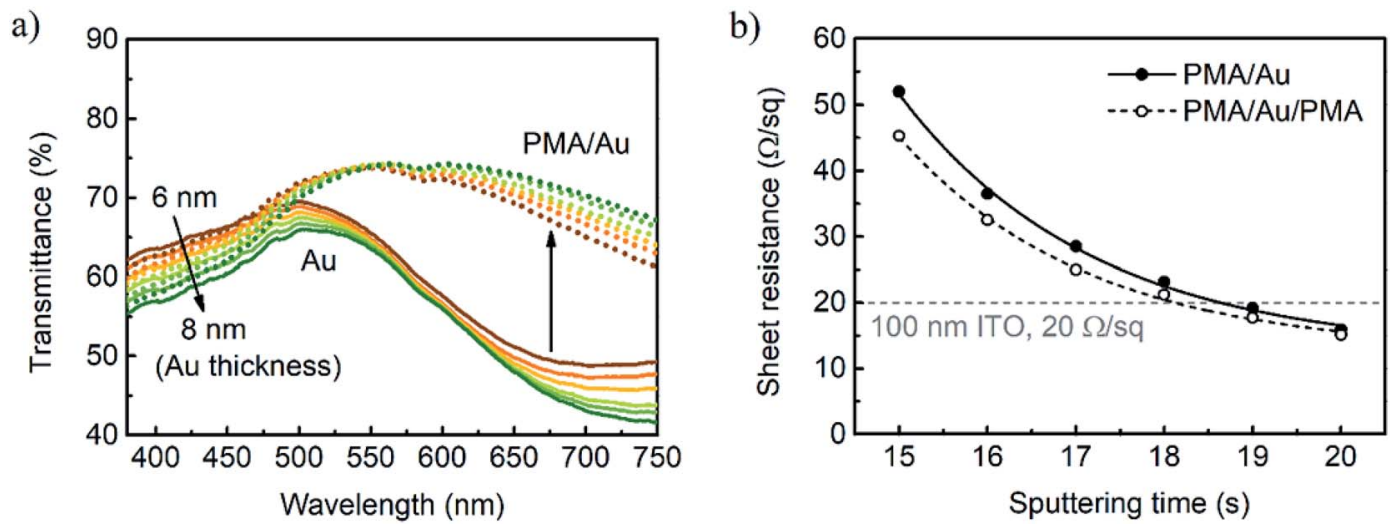

Fig. 1 (a) Transmittance of Au films with different thickness sputtered on quartz. (b) Sheet resistance of Au thin films with different thickness deposited on PMA or sandwiched between PMA films and annealed at $150{ }^{\circ} \mathrm{C}$. 
much lower than Au on bare glass $0.48 \mathrm{~nm}$. Both transmittance enhancement and sheet resistance reduction are the effect of continuous $\mathrm{Au}$ layer formation and support the claim that PMA enhances $\mathrm{Au}$ adhesion and supports grains coalescence. Results show that $1.2 \mathrm{~nm}$ of PMA layer is enough for transmittance enhancement in the visible light region and that thicker PMA layer has only a detrimental effect on transparency due to higher absorption of PMA in the UV range (Fig. S4a, ESI $\dagger$ ).

Further optimization of the MAM electrode was performed by comparing sheet resistance and transmittance of asdeposited PMA/Au films. It was decided that around $7 \mathrm{~nm} \mathrm{Au}$ (sputtered for $18 \mathrm{~s}$ ) is a fair compromise between transmittance in the visible light region and sheet resistance which is comparable to that of ITO substrates $\left(20 \Omega \mathrm{sq}^{-1}\right)$. Selected sample was coated with top PMA layer resulting in a reduction of light reflection and further transmittance enhancement as shown in Fig. 2a. The effect of top PMA thickness on PMA/Au/ PMA transmittance is shown in Fig. S4b (see ESI $\dagger$ ). Optimum transmittance was achieved for PMA concentration of $15 \mathrm{mg}$ $\mathrm{ml}^{-1}$ since the thicker film has started to reduce transmittance in the UV light region. It was discovered that top PMA helps to reduce sheet resistance after annealing at $150{ }^{\circ} \mathrm{C}$. This effect might be attributed to the enhancement of conductivity as a result of welding of $\mathrm{Au}$ film discontinuities rather than PMA itself because no noticeable resistance reduction was observed for non-annealed PMA/Au. Complete MAM multilayer is yellowish due to high reflectance at the blue light range. The champion MAM electrode has a peak transmittance of $80 \%$ and a sheet resistance of $21.7 \pm 0.5 \Omega \mathrm{sq}^{-1}$ (Fig. 2b).

\section{QLED device based on MAM electrode}

Optimized PMA/Au/PMA multilayer was investigated as a transparent conductive electrode integrated with QLED. A reference device has following structure: ITO (100 nm), reduced PMA (10 $\mathrm{nm})$, poly( $N, N^{\prime}$-bis(4-butylphenyl)- $N, N^{\prime}$-bis(phenyl)-benzidine) (pTPD, $22 \mathrm{~nm}$ ), poly(9-vinlycarbazole) (PVK, $8 \mathrm{~nm}$ ), QDs (25 nm), sol-gel derived $\mathrm{Zn}_{0.85} \mathrm{Mg}_{0.15} \mathrm{O}$ (ZnMgO, $35 \mathrm{~nm}$ ), and $\mathrm{Al}$ cathode $(100 \mathrm{~nm})$. QDs layer consists of 2 monolayers of green-emitting CdSe@ZnS/ZnS QDs with chemical composition-gradient
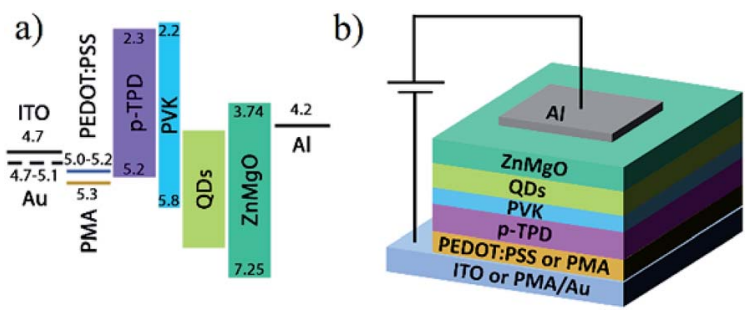

Fig. 3 (a) Energy band diagram of regular QLED with two different anodes: ITO or Au. (b) Device architecture.

structure and the average diameter of $13 \mathrm{~nm}$ which was determined from transmission electron microscopy (TEM) image (Fig. S5b, ESI $\dagger$ ). The photoluminescence quantum yield (PL QY) of QDs is 55\% and the PL peak is located at $515 \mathrm{~nm}$ (Fig. S5a, ESI $\dagger$ ). Additionally, the second reference device was prepared using poly(3,4-ethylenedioxythiophene) polystyrene sulfonate (PEDOT:PSS, $40 \mathrm{~nm}$ ) instead of PMA. The MAM-based device was fabricated on a glass substrate covered with PMA/Au/PMA multilayer. PMA/Au/PEDOT:PSS multilayer was not considered because of poor wettability of Au surface by PEDOT:PSS.

Energy band diagram of QLED and scheme of the device are shown in Fig. 3a and b. The work function (WF) of reduced PMA after annealing is close to $5.8 \mathrm{eV}$, while the conduction band (CB) is located $0.5 \mathrm{eV}$ above the Fermi level. ${ }^{44}$ The WF of typical $\mathrm{Au}$ film is in the range of $4.7-5.0 \mathrm{eV}$ and does not differ significantly from ITO WF $(4.7 \mathrm{eV})$. Small hole injection barrier is beneficial for charge generation at the HIL/HTL interface, where electrons are extracted from the HOMO level of p-TPD and transferred throughout CB of PMA towards Au electrode while generated holes are injected into the HTL. For all fabricated devices, sol-gel derived $\mathrm{Zn}_{1-x} \mathrm{Mg}_{x} \mathrm{O}(x=0.15)$ was applied as the electron transport layer (ETL). The optical bandgap of $\mathrm{ZnMgO}(3.5 \mathrm{eV})$ was estimated from absorbance (ABS) onset (see Fig. S6, ESI $\dagger$ ), and the valence band maximum was assumed to be consistent with the previous report. ${ }^{47}$

The performance of the QLED devices with different electrodes is summarized in Fig. $4 \mathrm{a}$ and $\mathrm{b}$. The turn-on voltages of all devices are nearly the same $(2.5 \mathrm{~V})$ and correspond closely to the bandgap of QDs $(2.41 \mathrm{eV})$ which is calculated from ABS
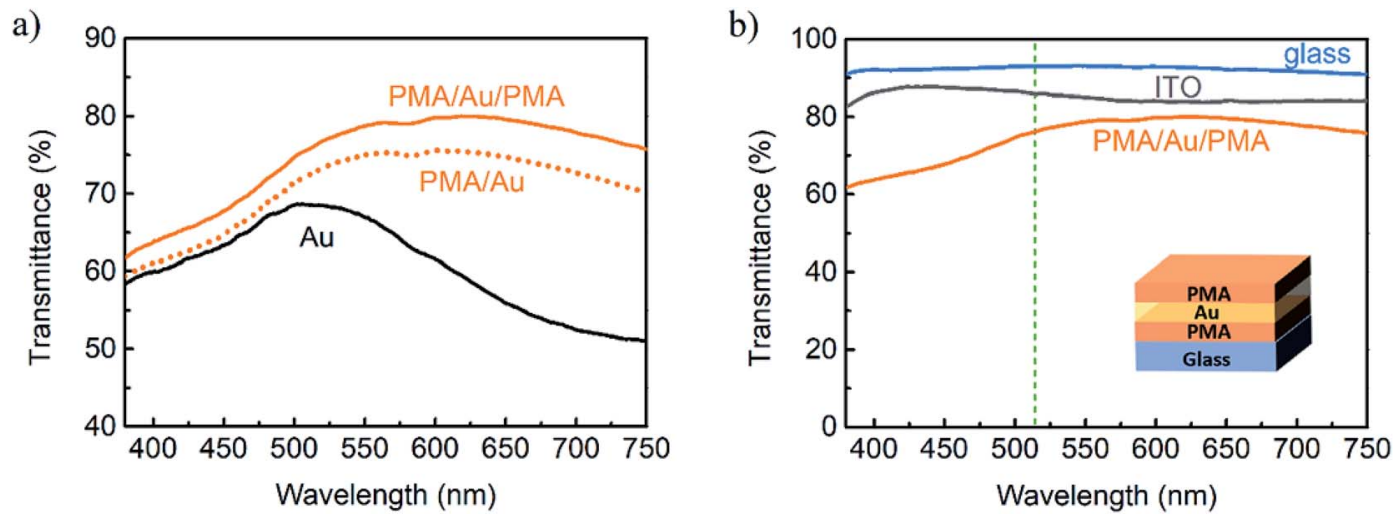

Fig. 2 (a) Transmittance of selected Au and corresponding PMA/Au thin films before and after deposition of the top PMA layer. (b) Transmittance of different electrodes on glass substrates: ITO and optimized MAM multilayer with around $7 \mathrm{~nm}$ Au film. Vertical dotted line indicates the maximum of QLED EL spectrum. 
a)

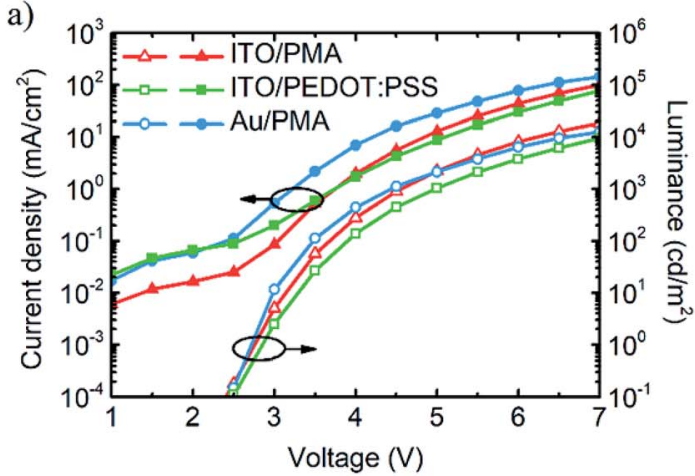

b)

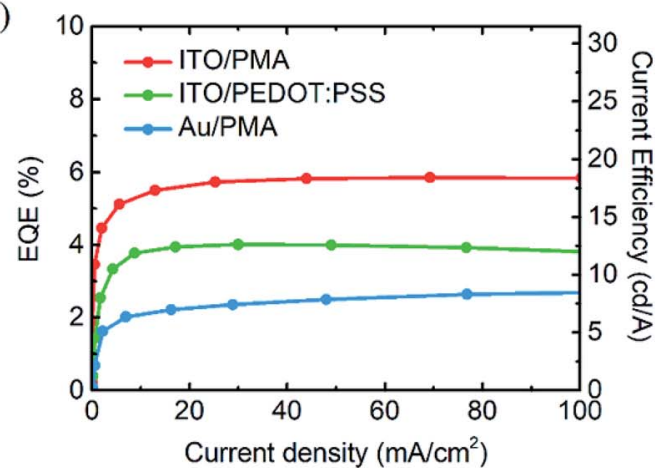

Fig. 4 (a) Current density-voltage-luminance $(J-V-L)$ characteristics of QLED device with ultrathin Au or ITO anode compared to standard device based on ITO/PEDOT:PSS. (b) EQE of the corresponding devices as a function of current density.

spectrum (Fig. S5a, ESI $\dagger$ ). The maximum values of external quantum efficiency (EQE) at $100 \mathrm{~mA} \mathrm{~cm}^{-2}$ of a reference QLEDs fabricated on ITO substrates with reduced PMA and PEDOT:PSS are $5.9 \%$ and $4.0 \%$ respectively (Fig. 4b). Device with MAM electrode deposited on a glass substrate has EQE of $2.7 \%$, although the luminance of all three devices is comparable. Electroluminescence (EL) spectrum of ITO-based QLED (shown in Fig. S8, ESI $\dagger$ ) is not shifted relative to QDs PL spectrum but the tail in the longer wavelengths region of the spectrum is visible. For MAM-based QLED, this tail is smaller, probably due to a weak cavity effect. The angular emission patterns for both ITO and MAM-based devices were shown in Fig. S8 (ESI $\dagger$ ). The Lambertian factor for standard ITO-based device was estimated at $0.94 \pi$ and it is very close to standard Lambertian emission. The MAM-based device exhibits a factor of $0.76 \pi$ that is related to more directional emission.
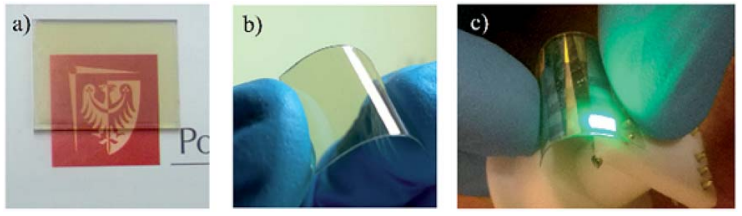

Fig. 5 Image of transparent MAM electrode on (a) glass and (b) flexible substrate. (c) Image of MAM-based flexible QLED at $7 \mathrm{~V}$.

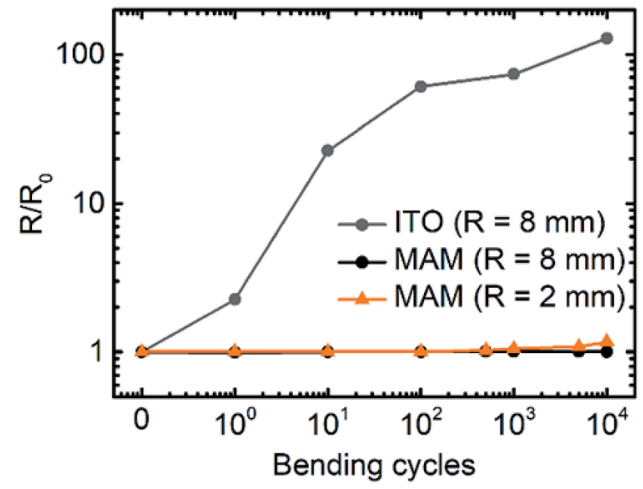

Fig. 6 Relative sheet resistance of flexible substrate with ITO or MAM electrode as a function of number of bending cycles with different radius.

\section{Flexible QLED based on MAM electrode}

We demonstrate that MAM multilayer electrode might be used for flexible QLED fabrication. Fig. 5a and b show MAM electrode on the glass and on the PET substrate. Bending tests were performed using different radii: $8 \mathrm{~mm}$ and $2 \mathrm{~mm}$. For this aim, the custom-made bending machine was built (Fig. S8, ESI $\dagger$ ). Sheet resistance measured after each number of cycles is shown in Fig. 6. In contrast to ITO-coated PET, sheet resistance of PET/ MAM substrate is nearly insensitive to bending and it is increased by less than $10 \%$ after over $10^{4}$ bending cycles using bending radius as small as $2 \mathrm{~mm}$.

\section{Conclusions}

To conclude, we have demonstrated a transparent conductive substrate composed of PMA/Au/PMA multilayer. The problem of the bottom PMA flushing was solved by PMA reduction. We discovered that the ultrathin PMA layer works as a wetting layer which enables uniform Au film to be sputtered. Based on these results, optimization of PMA/Au was performed, and we achieved a transmittance of $75 \%$ which was further enhanced after deposition of the top PMA. Consequently, complete PMA/Au/ PMA multilayer exhibited a peak transmittance of $80 \%$ and a sheet resistance of $21.7 \Omega \mathrm{sq}^{-1}$. MAM was applied to QLED as a bi-functional layer to serve as the HIL and a transparent electrode. The EQE of 2.7\% was achieved for MAM-based QLED, though its overall performance was lower than ITO-based counterpart which shows 5.7\% EQE. However, an important advantage of MAM electrode was highlighted by demonstrating its superior durability during rigorous bending tests. We believe that the proposed fabrication method of MAM electrode using sequential spin-coating and sputtering could be extended to other large-scale printing methods which might be the next step towards the fabrication of transparent flexible devices.

\section{Experimental details}

\section{Materials}

Reagents for the synthesis of QDs and sol-gel derived ZnMgO were delivered by Sigma-Aldrich and used as received, including cadmium oxide (CdO, 99.5\%), selenium (99.99\%), sulfur 
(99.98\%), trioctylphosphine (TOP, 97\%), zinc acetate $\left(\mathrm{Zn}(\mathrm{OAc})_{2}\right.$, 99.99\%), oleic acid (OA, 90\%), oleylamine (OAm, 70\%), 1-octadecene (ODE, 90\%), magnesium acetate tetrahydrate $\left(\mathrm{Mg}(\mathrm{OAc})_{2} \cdot 4 \mathrm{H}_{2} \mathrm{O}, 98.0 \%\right)$, monoethanolamine (MEA, 98.0\%), and 2-methoxyethanol (99.8\%). The materials for HTL deposition, p-TPD and PVK, were purchased from Ossila Ltd and Sigma Aldrich, respectively. PEDOT:PSS (AI 4083) was delivered by Ossila Ltd. Phosphomolybdic acid hydrate $\left(\mathrm{H}_{3}\left[\mathrm{P}\left(\mathrm{Mo}_{3} \mathrm{O}_{10}\right)_{4}\right]\right.$. $x \mathrm{H}_{2} \mathrm{O}$, PMAH, 99.9\%) used for preparation of HTL was purchased from Sigma Aldrich.

\section{Preparation}

CdSe@ZnS/ZnS QDs. Composition-gradient CdSe@ZnS core-shell QDs were prepared by modified procedure used by Lee et $a l .{ }^{48}$ Initially, mixture of $18 \mathrm{mg}$ of CdO $(0.14 \mathrm{mmol})$, $626 \mathrm{mg}$ of $\mathrm{Zn}(\mathrm{OAc})_{2}(3.41 \mathrm{mmol}), 7 \mathrm{ml}$ of $\mathrm{OA}(22 \mathrm{mmol})$, and $15 \mathrm{ml}$ of ODE were degassed in a $50 \mathrm{ml}$ three-neck flask for $30 \mathrm{~min}$ and then heated to $305{ }^{\circ} \mathrm{C}$ for $10 \mathrm{~min}$. The colourless solution was degassed for $10 \mathrm{~min}$. Then the temperature was raised to $310{ }^{\circ} \mathrm{C}$ and the colourless mixture of $\mathrm{S}(2.5 \mathrm{mmol})$ and Se (1.5 mmol) dissolved in $2 \mathrm{ml}$ of TOP was swiftly injected. QDs growth proceeded for 10 minutes and then S-ODE solution (1.6 mmol of $\mathrm{S}$ dissolved in $2.4 \mathrm{ml}$ of ODE) was injected to continue reaction for the next $10 \mathrm{~min}$. To coat compositiongradient QDs with a thick ZnS shell, separate solutions of zinc oleate $\mathrm{Zn}(\mathrm{OL})_{2}(8.5 \mathrm{ml}$ of stock solution) and S-TOP $(10 \mathrm{mmol}$ of $S$ dissolved in $5 \mathrm{ml}$ TOP) were slowly introduced for $10 \mathrm{~min}$. After $30 \mathrm{~min}$, the reaction mixture was cooled down. QDs were precipitated using ethanol and dispersed in hexane.

$\mathrm{Zn}(\mathrm{OL})_{2}$ stock solution. For the synthesis of $\mathrm{Zn}(\mathrm{OL})_{2}$ stock solution, $\mathrm{Zn}(\mathrm{OAc})_{2}(2 \mathrm{mmol}), \mathrm{OA}(4 \mathrm{mmol})$, and $6.7 \mathrm{ml}$ of ODE were loaded in a $50 \mathrm{ml}$ three-neck flask and degassed for $30 \mathrm{~min}$ at room temperature, and then heated to $200{ }^{\circ} \mathrm{C}$ under $\mathrm{N}_{2}$ atmosphere. After $10 \mathrm{~min}$, OAm ( $4 \mathrm{mmol}$ ) was added dropwise to the colourless solution of $\mathrm{Zn}(\mathrm{OL})_{2}$ to prevent solidification. The solution was maintained at $200{ }^{\circ} \mathrm{C}$ for the next $10 \mathrm{~min}$ and cooled to $120^{\circ} \mathrm{C}$. Then $16 \mathrm{ml}$ of ODE was added, and the stock solution was degassed under vacuum for the next $20 \mathrm{~min}$.

Sol-gel derived ZnMgO. $\mathrm{ZnO}$ doped with $15 \% \mathrm{Mg}$ was prepared by dissolving $213 \mathrm{mg}(1.16 \mathrm{mmol})$ of $\mathrm{Zn}(\mathrm{OAc})_{2}$ and $44 \mathrm{mg}$ of $\mathrm{Mg}(\mathrm{OAc})_{2} \cdot 4 \mathrm{H}_{2} \mathrm{O}(0.20 \mathrm{mmol})$ in 2-methoxyethanol mixed with $80 \mu \mathrm{l}$ of MEA $(1.32 \mathrm{mmol})$ as a complexing agent and $42 \mu \mathrm{l}$ of water. The mixture was heated for $2 \mathrm{~h}$ at $60{ }^{\circ} \mathrm{C}$ and the clear solution was aged for 1 day before deposition.

PMA/Au electrode. Transparent PMA/Au electrode was deposited sequentially on quartz coated glass (Ossila Ltd) by spin-coating and sputtering. Firstly, PMAH crystals were dehydrated and reduced by being annealed at $200{ }^{\circ} \mathrm{C}$ in $\mathrm{N}_{2}$ atmosphere for $5 \mathrm{~h}$, and obtained powder was dissolved in isopropanol to produce dark bluish solution which was purified using $0.1 \mu \mathrm{m}$ PTFE syringe filter. Reduced PMA solution with different concentration was spin-coated at $4000 \mathrm{rpm}$ on substrates and annealed at $90{ }^{\circ} \mathrm{C}$ for $10 \mathrm{~min}$. Subsequently, 6$8 \mathrm{~nm}$ of gold was deposited by magnetron sputtering in $\mathrm{Ar}$ plasma at a rate of $6 \AA^{\circ} \mathrm{s}^{-1}$ and the thickness of Au film was varied by controlling the sputtering time. High repeatability of that process was verified by comparing transmittance spectra and sheet resistances of thin films.

\section{Device fabrication}

Devices were fabricated in the nitrogen-filled glovebox on either ITO or PMA/Au electrodes. ITO substrates were cleaned sequentially with detergent, deionized water, isopropanol, and were treated for $15 \mathrm{~min}$ in UV-ozone cleaner. PMA/Au substrates were used without any treatment. Reduced PMA was spincoated (4000 rpm, $30 \mathrm{~s}$ ) and annealed at $90{ }^{\circ} \mathrm{C}$ for $10 \mathrm{~min}$. PEDOT:PSS was spin-coated (4000 rpm, $45 \mathrm{~s}$ ) followed by baking at $150{ }^{\circ} \mathrm{C}$ for $10 \mathrm{~min}$ in air. Double HIL composed of p-TPD and PVK was deposited by sequential spin-coating of p-TPD $(10 \mathrm{mg}$ $\mathrm{ml}^{-1}$ in chlorobenzene) and PVK (2.5 $\mathrm{mg} \mathrm{ml}^{-1}$ in 1,4-dioxane) at $4000 \mathrm{rpm}$ for $30 \mathrm{~s}$ and each layer was annealed at $140{ }^{\circ} \mathrm{C}$ for $20 \mathrm{~min}$. Then QDs dispersion (10 $\mathrm{mg} \mathrm{ml}^{-1}$ in octane/hexane) was spin-coated at $2000 \mathrm{rpm}$ for $20 \mathrm{~s}$ and annealed at $80{ }^{\circ} \mathrm{C}$ for $10 \mathrm{~min}$. ZnMgO sol was spin-coated at $4000 \mathrm{rpm}$ and formed a gel which was annealed at $150{ }^{\circ} \mathrm{C}$ for $15 \mathrm{~min}$. Finally, $100 \mathrm{~nm}$ thick $\mathrm{Al}$ cathodes were sputtered. An emitting area of a pixel was estimated at $4.5 \mathrm{~mm}^{2}$. For the flexible device, to prevent deformation of PET substrate, annealing temperatures of HTL and ETL were reduced to $110{ }^{\circ} \mathrm{C}$.

\section{Measurements}

$J-V-L$ and EQE- $J$ curves were measured using Keithley 2400 source-meter coupled with Konica Minolta LS-160 luminance meter. The angular emission pattern was measured using the luminance meter and a rotating stage. A calculated correction factor was used for EQE calculations. PL QY of QDs was estimated using the integration sphere (Gigahertz-Optic UPB-150ART). UV-Vis PL spectra of QDs were collected by an optical fiber and recorded using CCD spectrometer (AvaSpecULS2048XL), and $405 \mathrm{~nm}$ laser diode was used for excitation. A deuterium-halogen lamp was a broadband light source for ABS measurements. The sheet resistance of conductive substrates was measured using Ossila Four-Point Probe System. High-resolution transmission microscopy (HR-TEM) image of QDs was taken by JEOL-ARM-200F microscope. The thickness of thin films was determined by Park Systems AFM.

\section{Conflicts of interest}

There are no conflicts to declare.

\section{Acknowledgements}

The authors acknowledge the National Science Centre for their financial support within the OPUS 14 project no. 2017/27/B/ST5/ 01209 and SONATA 8 project no. 2014/15/D/ST5/02744.

\section{Notes and references}

1 S. R. Forrest, Nature, 2004, 428, 911-918.

2 M. K. Choi, J. Yang, T. Hyeon and D.-H. Kim, npj Flexible Electronics, 2018, 2, 10. 
3 S.-H. Jeong, S.-H. Woo, T.-H. Han, M.-H. Park, H. Cho, Y.-H. Kim, H. Cho, H. Kim, S. Yoo and T.-W. Lee, NPG Asia Mater., 2017, 9, e411.

4 M. Vosgueritchian, D. J. Lipomi and Z. Bao, Adv. Funct. Mater., 2012, 22, 421-428.

5 J. Krantz, T. Stubhan, M. Richter, S. Spallek, I. Litzov, G. J. Matt, E. Spiecker and C. J. Brabec, Adv. Funct. Mater., 2013, 23, 1711-1717.

6 T.-H. Han, Y. Lee, M.-R. Choi, S.-H. Woo, S.-H. Bae, B. H. Hong, J.-H. Ahn and T.-W. Lee, Nat. Photonics, 2012, 6, 105-110.

7 S. Bae, H. Kim, Y. Lee, X. Xu, J.-S. Park, Y. Zheng, J. Balakrishnan, T. Lei, H. Ri Kim, Y. Il Song, Y.-J. Kim, K. S. Kim, B. Özyilmaz, J.-H. Ahn, B. H. Hong and S. Iijima, Nat. Nanotechnol., 2010, 5, 574-578.

8 K. S. Kim, Y. Zhao, H. Jang, S. Y. Lee, J. M. Kim, K. S. Kim, J.-H. Ahn, P. Kim, J.-Y. Choi and B. H. Hong, Nature, 2009, 457, 706-710.

9 O. Urper, İ. Çakmak and N. Karatepe, Mater. Lett., 2018, 223, 210-214.

10 Z. Wu, Z. Chen, X. Du, J. M. Logan, J. Sippel, M. Nikolou, K. Kamaras, J. R. Reynolds, D. B. Tanner, A. F. Hebard and A. G. Rinzler, Science, 2004, 305, 1273-1276.

11 M.-G. Kang, M.-S. Kim, J. Kim and L. J. Guo, Adv. Mater., 2008, 20, 4408-4413.

12 J.-S. Yu, G. H. Jung, J. Jo, J. S. Kim, J. W. Kim, S.-W. Kwak, J.-L. Lee, I. Kim and D. Kim, Sol. Energy Mater. Sol. Cells, 2013, 109, 142-147.

13 R. Wang, C. Fan, Z. Xiong, X. Yang and G. E. Jabbour, Org. Electron., 2015, 19, 105-112.

14 J. Jin, J. Lee, S. Jeong, S. Yang, J.-H. Ko, H.-G. Im, S.-W. Baek, J.-Y. Lee and B.-S. Bae, Energy Environ. Sci., 2013, 6, 1811.

15 W. Cao, Y. Zheng, Z. Li, E. Wrzesniewski, W. T. Hammond and J. Xue, Org. Electron., 2012, 13, 2221-2228.

16 B. Tian, G. Williams, D. Ban and H. Aziz, J. Appl. Phys., 2011, 110, 104507.

17 S. Lenk, T. Schwab, S. Schubert, L. Müller-Meskamp, K. Leo, M. C. Gather and S. Reineke, Appl. Phys. Lett., 2015, 107, 163302.

18 D. Jeong, C. Lim, M. Kim, K. Jeong, J.-H. Kim, J. Kim, J.-G. Park, K.-S. Min and J. Lee, Electron. Mater. Lett., 2017, 13, 16-24.

19 X. Yang, E. Mutlugun, C. Dang, K. Dev, Y. Gao, S. T. Tan, X. W. Sun and H. V. Demir, ACS Nano, 2014, 8, 8224-8231.

20 G. Liu, X. Zhou and S. Chen, ACS Appl. Mater. Interfaces, 2016, 8, 16768-16775.

21 T. W. Ebbesen, H. J. Lezec, H. F. Ghaemi, T. Thio and P. A. Wolff, Nature, 1998, 391, 667-669.

22 M. Maniruzzaman, M. A. Rahman, K. Jeong, H. Nam and J. Lee, Renewable Energy, 2014, 71, 193-199.

23 L. Shi, Y. Cui, Y. Gao, W. Wang, Y. Zhang, F. Zhu, Y. Hao, L. Shi, Y. Cui, Y. Gao, W. Wang, Y. Zhang, F. Zhu and Y. Hao, Nanomaterials, 2018, 8, 473.
24 R. Capelli, S. Toffanin, G. Generali, H. Usta, A. Facchetti and M. Muccini, Nat. Mater., 2010, 9, 496-503.

25 T.-H. Yeh, C.-C. Lee, C.-J. Shih, G. Kumar, S. Biring and S.-W. Liu, Org. Electron., 2018, 59, 266-271.

26 H. W. Choi, N. D. Theodore and T. L. Alford, Sol. Energy Mater. Sol. Cells, 2013, 117, 446-450.

27 X. Liu, X. Cai, J. Qiao 1, J. Mao and N. Jiang 1, Thin Solid Films, 2003, 441, 200-206.

28 M. Maniruzzaman, M. Arifur Rahman, K. Jeong and J. Lee, Mater. Sci. Semicond. Process., 2014, 27, 114-120.

29 X. Yang, P. Gao, Z. Yang, J. Zhu, F. Huang and J. Ye, Sci. Rep., 2017, 7, 44576.

30 D. Ebner, M. Bauch and T. Dimopoulos, Opt. Express, 2017, 25, A240.

31 R. Henriquez, S. Bravo, R. Roco, V. Del Campo, D. Kroeger and P. Häberle, Metall. Mater. Trans. A, 2019, 50, 493-503.

32 S. Hafezian, B. Baloukas and L. Martinu, Appl. Opt., 2014, 53, 5367.

33 P. Malinský, P. Slepička, V. Hnatowicz and V. Svorčík, Nanoscale Res. Lett., 2012, 7, 241.

34 J. Siegel, O. Lyutakov, V. Rybka, Z. Kolská and V. Švorčík, Nanoscale Res. Lett., 2011, 6, 96.

35 S. Ohisa, S. Kagami, Y.-J. Pu, T. Chiba and J. Kido, ACS Appl. Mater. Interfaces, 2016, 8, 20946-20954.

36 W. Qiu, A. Hadipour, R. Müller, B. Conings, H.-G. Boyen, P. Heremans and L. Froyen, ACS Appl. Mater. Interfaces, 2014, 6, 16335-16343.

37 K. Zilberberg, H. Gharbi, A. Behrendt, S. Trost and T. Riedl, ACS Appl. Mater. Interfaces, 2012, 4, 1164-1168.

$38 \mathrm{~J}$. Meyer, R. Khalandovsky, P. Görrn and A. Kahn, Adv. Mater., 2011, 23, 70-73.

39 Y. Li, H. Yu, X. Huang, Z. Wu and M. Chen, RSC Adv., 2017, 7, 7890-7900.

40 Y. Zhu, Z. Yuan, W. Cui, Z. Wu, Q. Sun, S. Wang, Z. Kang and B. Sun, J. Mater. Chem. A, 2014, 2, 1436-1442.

41 X. Jia, L. Shen, M. Yao, Y. Liu, W. Yu, W. Guo and S. Ruan, ACS Appl. Mater. Interfaces, 2015, 7, 5367-5372.

42 Y. Liu, C. Jiang, C. Song, J. Wang, L. Mu, Z. He, Z. Zhong, Y. Cun, C. Mai, J. Wang, J. Peng and Y. Cao, ACS Nano, 2018, 12, 1564-1570.

43 D. Dong, L. Lian, H. Wang and G. He, Org. Electron., 2018, 62, 320-326.

44 S. Ohisa, K. Endo, K. Kasuga, M. Suzuki, T. Chiba, Y.-J. Pu and J. Kido, Inorg. Chem., 2018, 57, 1950-1957.

45 K. Sivaramakrishnan and T. L. Alford, Appl. Phys. Lett., 2010, 96, 201109.

46 A. Axelevitch, B. Apter and G. Golan, Opt. Express, 2013, 21, 4126.

47 L. Hu, D.-B. Li, L. Gao, H. Tan, C. Chen, K. Li, M. Li, J.-B. Han, H. Song, H. Liu and J. Tang, Adv. Funct. Mater., 2016, 26, 1899-1907.

48 K.-H. Lee, J.-H. Lee, H.-D. Kang, B. Park, Y. Kwon, H. Ko, C. Lee, J. Lee and H. Yang, ACS Nano, 2014, 8, 4893-4901. 